\title{
AISI 304 steel: anomalous evolution of martensitic phase following heat treatments at $400{ }^{\circ} \mathrm{C}$
}

\author{
F. Gauzzi ${ }^{\text {a }}$, R. Montanari ${ }^{\text {a,* }}$, G. Principi ${ }^{\text {b }}$, M.E. Tata ${ }^{\mathrm{a}}$ \\ a Dipartimento di Ingegneria Meccanica- Università di Roma-Tor Vergata, Rome, Italy \\ ${ }^{\mathrm{b}}$ Dipartimento di Ingegneria Meccanica-Sezione Materiali, Università di Padova, Padova, Italy \\ Received 28 April 2005; received in revised form 18 November 2005; accepted 28 February 2006
}

\begin{abstract}
AISI 304 steel with a biphasic structure $\left(\alpha^{\prime}+\gamma\right)$, induced by plastic deformation at room temperature, shows an anomalous evolution of martensite content when heated at $400^{\circ} \mathrm{C}$. High-temperature X-ray diffraction has been used to investigate the phenomenon. Isothermal measurements at $400^{\circ} \mathrm{C}$ for times up to $2.0 \times 10^{4} \mathrm{~s}$ show that martensite progressively transforms to austenite but an increase of martensite content is observed after cooling to room temperature. The result confirms that the heat treatment causes composition inhomogeneities and a local increase of $M_{\mathrm{S}}$ (martensite start temperature) in the zones depleted of alloying elements so that a certain amount of martensite can form during cooling to room temperature. The temperature range of martensitic transformation is $240-190{ }^{\circ} \mathrm{C}$ and was determined by dynamic modulus measurements.
\end{abstract}

(C) 2006 Elsevier B.V. All rights reserved.

Keywords: Martensite reversion; AISI 304 steel; Magnetic peak; High-temperature X-ray diffraction; Dynamic modulus

\section{Introduction}

Following heat treatments at a temperature of about $400^{\circ} \mathrm{C}$ an increase of martensite content takes place in austenitic stainless steels with biphasic structure (martensite $\alpha^{\prime}+$ austenite $\gamma$ ) producing an increase of yield stress and ultimate tensile strength [1-2]. Controversial results made difficult to explain the anomalous phenomenon, which occurs in materials where martensite is induced by both cooling and deformation [3]. Smith and West [4] ascribed "the magnetic peak at $400^{\circ} \mathrm{C}$ " to the formation of a ferrite $\alpha$ as an intermediate stage of the $\alpha^{\prime} \rightarrow \gamma$ reversion. Magnetic measurements, performed directly at the annealing temperature, showed no evidence of variations of $\alpha^{\prime}$ phase volume fraction [5]. On the basis of this result, Harries [6] argued that the heat treatment induces a fine carbide precipitation, which lowers the content of alloying elements in solid solution with consequent increase of the martensite start $\left(M_{\mathrm{S}}\right)$ temperature: new $\alpha^{\prime}$ phase can form during cooling to room temperature.

\footnotetext{
* Corresponding author at: Roberto Montanari, Dipartimento di Ingegneria Meccanica - Università di Roma-Tor Vergata, Via del Politecnico, 1 - I-00133 Rome, Italy. Tel.: +390672 597 182; fax: +39062021 351.

E-mail address: roberto.montanari@uniroma2.it (R. Montanari).
}

One of us investigated AISI 304 samples with different initial martensite volume fractions (up to 84\%) [7]. The samples were submitted to annealing at $400{ }^{\circ} \mathrm{C}$ for increasing times and the amount of $\alpha^{\prime}$ phase was determined by X-ray diffraction (XRD) at room temperature. For all the samples the amount of $\alpha^{\prime}$ phase plotted versus annealing time showed a overall decreasing trend, due to $\alpha^{\prime} \rightarrow \gamma$ reversion. Superimposed to this trend two relative maxima after $\approx 4 \times 10^{3} \mathrm{~s}$ and $3.5 \times 10^{4} \mathrm{~s}$ were observed. The first maximum was attributed to the growth of martensitic zones when microstresses relax in the surrounding austenitic phase due to recovery of defective structures (dislocations and stacking faults) following the treatment. This interpretation was confirmed by further results, in particular by Mössbauer spectroscopy (MS) data [8].

The explanation of the second maximum was given assuming operative the mechanism described by Harries [6], which is supported by MS experiments evidencing that long time of annealing at $400{ }^{\circ} \mathrm{C}$ produces a lowering of alloying elements in martensite without a corresponding composition change in austenite [8] and by acoustic emission (AE) detected during cooling [9].

This work has been carried out to achieve further information on the origin of the second maximum by means of hightemperature XRD and dynamic modulus measurements. 


\section{Material and experimental}

The AISI 304 steel has the following nominal chemical composition (wt.\%): C 0.06, Ni 8.60, Cr 18.25, Mn 0.82, Mo 0.16, $\mathrm{S}$ 0.015, P 0.021, Si 0.56, Ti, Cu, V traces, Fe to balance.

The samples were preliminary heated for $1.8 \times 10^{3} \mathrm{~s}$ at $1050{ }^{\circ} \mathrm{C}$ and then water quenched. After this treatment, the structure is fully austenitic ( $\gamma$ phase), martensite ( $\alpha^{\prime}$ phase) was induced by cold rolling at room temperature. The samples examined here had an initial martensite content of $94 \%$, higher than those investigated in previous experiments [7-8].

They were studied by high-temperature XRD during annealing in argon atmosphere at $400^{\circ} \mathrm{C}$ for times up to $2.0 \times 10^{4} \mathrm{~s}$. The experiments were performed by means of an hightemperature X-ray camera (Anton Paar HT 1600) using MoK $\alpha$ radiation $(\lambda=0.71 \AA)$.

For monitoring the microstructural evolution of the samples, the line profiles of $\{220\} \gamma$ and $\{211\} \alpha^{\prime}$ reflections were continuously recorded in the $2 \Theta$ angular range $31-36^{\circ}$ by step scanning with steps of $0.01^{\circ}$ and counting times of $2 \mathrm{~s}$ for each step. The time of each measurement run was $1.0 \times 10^{3} \mathrm{~s}$, so 20 spectra have been collected during the entire heat treatment. Before and after the measurement cycle the complete XRD patterns were recorded over a $2 \Theta$ range from $15^{\circ}$ to $55^{\circ}$.

Another series of measurements was carried out to understand how the steel changes during heating to $400^{\circ} \mathrm{C}$. In this case, the material was heated to the final temperature $\left(400^{\circ} \mathrm{C}\right)$ passing through intermediate annealing stages of $3.6 \times 10^{3} \mathrm{~s}$ at 100,200 and $300^{\circ} \mathrm{C}$.

The volume fractions of the phases were determined from the peak integrated intensities $I_{h k l}$ after background subtraction.

Dynamic modulus measurements have been carried out on bar-shaped samples using the method of frequency modulation. The resonance frequency $f$ was monitored at time intervals of $60 \mathrm{~s}$ during heat treatments at $400{ }^{\circ} \mathrm{C}$ and subsequent cooling to room temperature. Since the dynamic modulus is proportional to $f^{2}$ [10], its evolution is described by $\left(f / f_{0}\right)^{2}$ where $f_{0}$ is the resonance frequency of the as-deformed material at room temperature. The strain amplitude was kept lower than $1 \times 10^{-6}$.

\section{Results}

In Fig. 1 the XRD spectra collected at room temperature before and after the isothermal measurement cycle are displayed. After annealing $\left(2.0 \times 10^{4} \mathrm{~s}\right.$ at $\left.400^{\circ} \mathrm{C}\right)$ the $\{111\},\{200\}$, $\{220\},\{3111\}$ and $\{420\} \gamma$ reflections are detected whereas only the $\{220\} \gamma$ reflection was present before. The austenite content, which was $6 \%$ in the as-deformed sample, increases to $37 \%$ after the heat treatment.

Since the diffraction patterns of deformed samples show only one $\gamma$ reflection, the structure evolution during annealing has been monitored by recording a small part of the spectrum $(2 \Theta$ range from $31^{\circ}$ to $36^{\circ}$ ) including $\{220\} \gamma$ and $\{211\} \alpha^{\prime}$ reflections. Fig. 2a shows these peaks at room temperature and at $400{ }^{\circ} \mathrm{C}$ after successive heat treatment steps. The peaks collected at high temperature result shifted towards lower angles due to thermal lattice expansion. Moreover, as the annealing

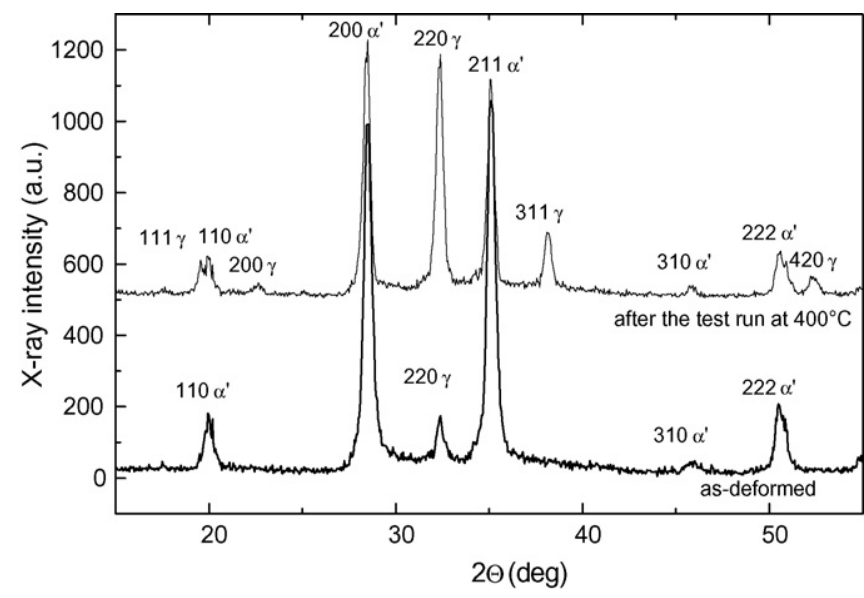

Fig. 1. XRD spectra of the samples in as-deformed condition and after the measurement cycle at $400{ }^{\circ} \mathrm{C}$ for $2.0 \times 10^{4} \mathrm{~s}$

proceeds the intensity of $\{220\} \gamma$ peak increases whereas that of $\left\{\begin{array}{lll}2 & 1 & 1\end{array}\right\} \alpha^{\prime}$ peak decreases indicating the progressive austenite reversion. From the patterns in a, the ratios $I_{\alpha} / I_{\gamma}$ between the intensities of the two peaks have been determined (Fig. 2b). The ratio exhibits a descending trend versus annealing time; it is noteworthy that the martensite fraction increases after cooling to room temperature (last point of the curve). The change of relative intensities is also displayed by Fig. 3 .

The half-height linewidths $\beta$ of precision profiles in Fig. 2a provide an indication about the evolution of defective structures, in particular dislocations, in the two phases. The $\beta$-value of the $(211)_{\alpha}$ reflection markedly decreases during heating to $400{ }^{\circ} \mathrm{C}$, then continues to slowly decrease up to $\sim 1.5 \times 10^{3} \mathrm{~s}$ of annealing, finally remains substantially constant exhibiting small fluctuations, comparable to the experimental error. The progressive narrowing of peak profile is due to the annealing out of lattice defects and is much more evident in martensite than in austenite.

To find the temperature range where the martensitic transformation occurs, dynamic modulus measurements have been performed under different conditions of thermal cycle. Fig. 4 shows modulus trend and temperature profile recorded during cooling of a sample, which was maintained at $400^{\circ} \mathrm{C}$ for $7.2 \times 10^{3} \mathrm{~s}$. Time scale refers to the start of sample heating. The modulus trend clearly exhibits an anomaly (part between arrows in Fig. 4) in the temperature range $240-190{ }^{\circ} \mathrm{C}$. The anomaly consists of a minimum overlapping the continuously increasing trend and depends on the movement of $\alpha^{\prime} / \gamma$ interfaces. Its initial and final points substantially indicate start and finish of the martensitic transformation.

The same procedure has been used to investigate the behaviour of several samples kept at $400{ }^{\circ} \mathrm{C}$ for different times in the range from $3.6 \times 10^{3}$ to $1.8 \times 10^{4} \mathrm{~s}$. The temperatures of martensite start and finish showed variations within $\pm 2 \mathrm{~K}$, comparable with the experimental error, thus the temperature range of martensitic transformation appears scarcely affected by the annealing time at $400^{\circ} \mathrm{C}$. Other experiments are underway to assess whether initial and final transformation temperatures are affected by cooling rate. 

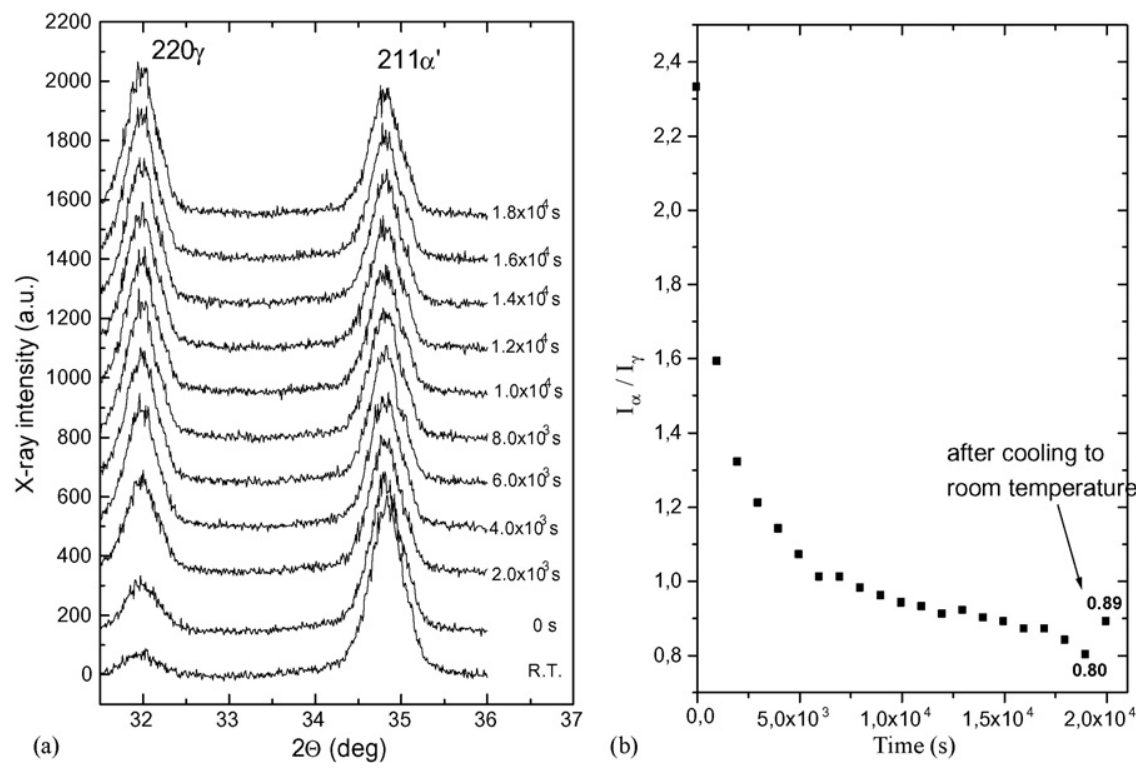

Fig. 2. (a) XRD spectra of the same sample in as-deformed condition at room temperature (R.T.) and at $400{ }^{\circ} \mathrm{C}$ after successive steps of annealing. (b) Ratio $\left(I_{\alpha} / I_{\gamma}\right)$ of $\{211\} \alpha^{\prime}$ and $\{220\} \gamma$ peak intensities vs. annealing time. Data determined from spectra in (a).

Fig. 5a shows the spectra recorded during the second series of measurements where the sample was heated to $400^{\circ} \mathrm{C}$ with intermediate isothermal steps of $3.6 \times 10^{3} \mathrm{~s}$ at 100,200 and $300^{\circ} \mathrm{C}$. During each step two XRD patterns have been recorded: the first one (marked by 1-) at the beginning of the step, the second one (marked by 2 -) after $2.6 \times 10^{3} \mathrm{~s}$. The XRD spectra at room temperature of the sample in as-deformed condition and after cooling are also displayed. The intensity ratios $I_{\alpha} / I_{\gamma}$ determined from spectra 1 and 2 of each isothermal step are plotted in Fig. 5b. The texture change, evidenced by variations of relative intensities of XRD reflections, could be due either to phase transformation or to recrystallization. Since the temperatures involved here are too low to produce significant recrystallization in AISI 304 steel, the increase of $I_{\alpha} / I_{\gamma}$ can be attributed to the formation of new martensite during the $200^{\circ}$ and $300^{\circ} \mathrm{C}$ annealing steps. At $400^{\circ} \mathrm{C}$ the $\alpha^{\prime} \rightarrow \gamma$ transformation is prevailing.

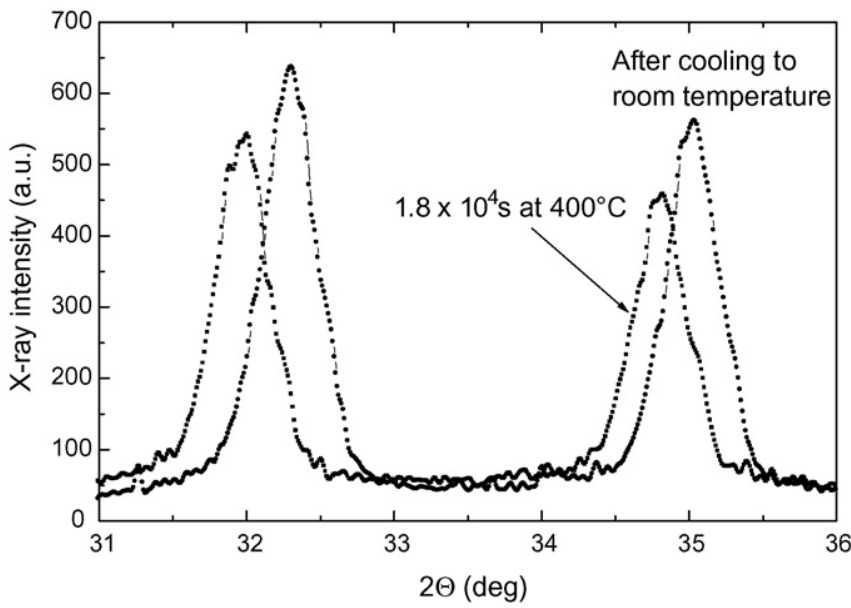

Fig. 3. XRD spectra of the same sample at $400^{\circ} \mathrm{C}$ after $1.8 \times 10^{4} \mathrm{~s}$ of annealing and after subsequent cooling to room temperature.

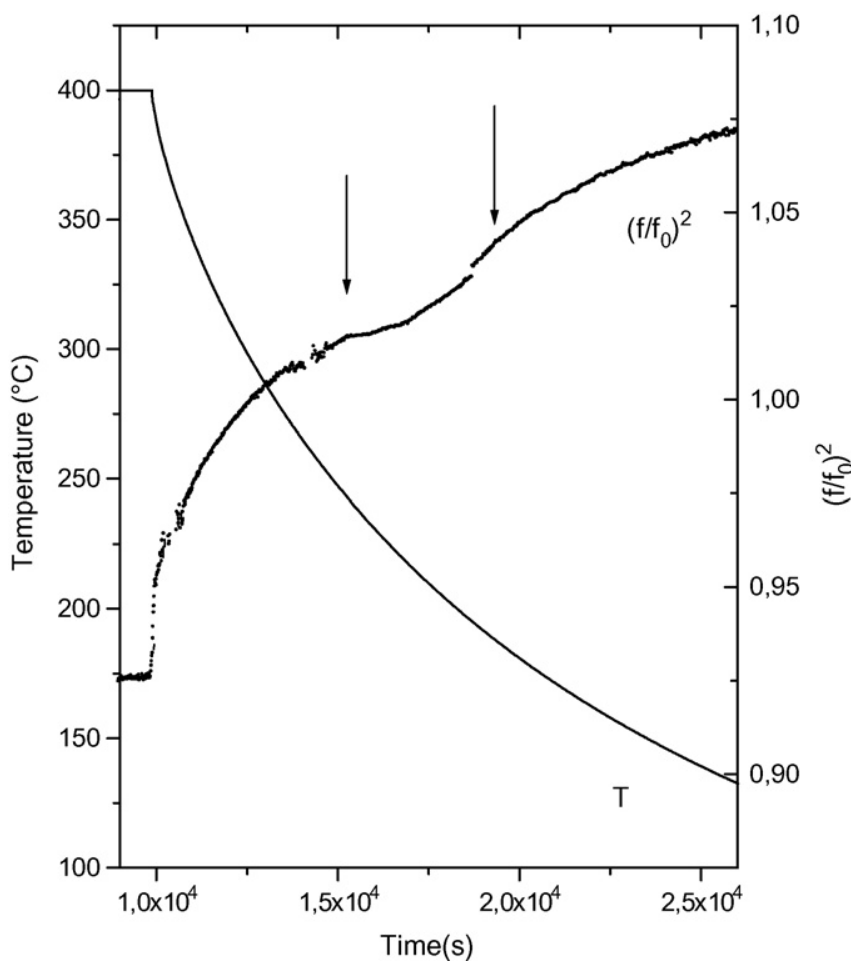

Fig. 4. Dynamic modulus and temperature profile recorded during cooling. Arrows indicate the range where the modulus exhibits an anomalous trend associated to the martensitic transformation.

The half-height linewidths $\beta$, corrected from experimental broadening, determined from spectra 1 and 2 at 200 and $300^{\circ} \mathrm{C}$ are also reported in Fig. $5 b$.

\section{Discussion}

High-temperature XRD clearly shows that the $\alpha^{\prime} \rightarrow \gamma$ transformation is the prevailing phenomenon occurring during 

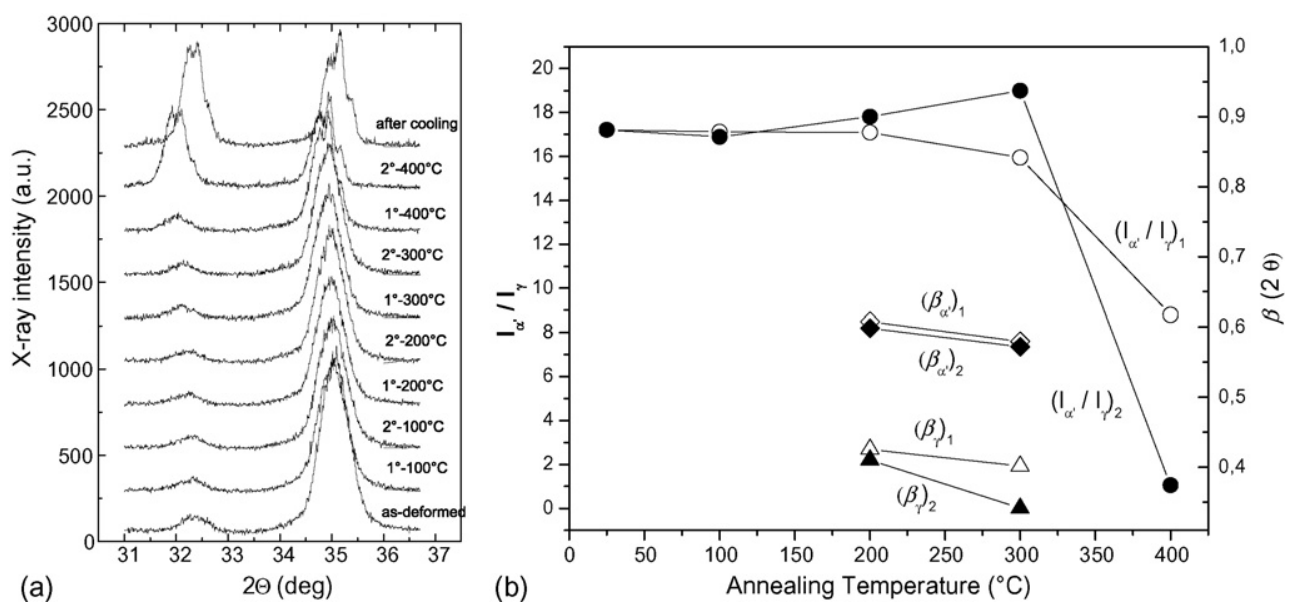

Fig. 5. (a) XRD spectra of the same sample at room temperature, during successive annealing steps of $3.6 \times 10^{3} \mathrm{~s}$ at $100,200,300$ and $400{ }^{\circ} \mathrm{C}$ and after cooling. For each step, two measurement runs have been carried out: the first one (1-) at the beginning of the stage, the second one (2-) after $2.6 \times 10^{3} \mathrm{~s}$. (b) Ratios of $\{211\} \alpha^{\prime}$ and $\{220\}$ ( peak intensities in the first $\left(I_{\alpha} / I_{\gamma}\right)_{1}$ and second $\left(I_{\alpha} / I_{\gamma}\right)_{2}$ measurement runs. The half-height linewidths $\beta$ of the martensite and austenite peaks recorded at 200 and $300{ }^{\circ} \mathrm{C}$ during first and second runs are reported too. All the data determined from spectra in (a).

annealing at $400^{\circ} \mathrm{C}$. After the measurement cycle $\left(2.0 \times 10^{4} \mathrm{~s}\right)$ the relative amounts of the two phases has changed: austenite content, which was $6 \%$ in the as-deformed sample, increases to $37 \%$. However, when the steel is cooled down to room temperature a certain amount of austenite transforms to martensite (Fig. 3). Since the $M_{\mathrm{S}}$ temperature of AISI 304 steel is far below room temperature, the formation of some martensite by cooling involves the presence of composition inhomogeneities, which locally increase $M_{\mathrm{S}}$ in the zones impoverished of alloying elements and permit the martensitic transformation to take place. This is in good agreement with previous results [8-9] and further supports the mechanism proposed by Harries [6] even if it is not yet clear the physical origin of compositional fluctuations. Harries suggested that heat treatment induces a fine carbide precipitation but, in fact, TEM observations performed by Mangonon \& Thomas [11] and by us [12] were not able to evidence precipitates inside the new $\alpha^{\prime}$ crystals which have a lenticular shape, as martensite in $\mathrm{Fe}-\mathrm{C}$ and $\mathrm{Fe}-\mathrm{Ni}-\mathrm{C}$ alloys, different from that of strain-induced martensite.

The martensitic transformation taking place during cooling causes the anomalous trend of dynamic modulus shown in Fig. 4. Initial and final points of the anomaly indicate that the transformation occurs in the temperature range $240-190^{\circ} \mathrm{C}$. The result is compatible with the range $330-100^{\circ} \mathrm{C}$ reported by Mukhopadhyay et al. [9] after AE experiments.

The second series of high-temperature XRD measurements shows that some martensite forms during the heating steps at 200 and $300^{\circ} \mathrm{C}$ whereas at $400^{\circ} \mathrm{C}$ the $\alpha^{\prime} \rightarrow \gamma$ transformation is the dominant process (Fig. 5a and b). Martensite formation at 200 and $300{ }^{\circ} \mathrm{C}$ occurs progressively since the $I_{\alpha} / I_{\gamma}$ ratio of the second diffraction pattern recorded at each step is always higher than that of the first one.

This phenomenon can be explained by considering the different recovery of austenite and martensite (see half-height linewidths $\beta$ in Fig. 5b). $\beta$-values of austenite peak in the second spectra recorded at 200 and in particular at $300{ }^{\circ} \mathrm{C}$ show a remarkable decrease with respect those of the first ones. The variations of those of martensite are very small. Therefore, isothermal steps have the effect to relax stresses more in austenite than in martensite and cause non-equilibrium conditions at the $\alpha^{\prime} / \gamma$ interfaces. A net gradient of stress act on the interface and force it to move towards the phase where the stress is lower, i.e., austenitic phase. The result is an increase of martensite volume. The net variation is relatively small because the initial martensite content is very high (94\%). As mentioned in the introduction, the same phenomenon appears during annealing at $400^{\circ} \mathrm{C}$ in samples with lower initial martensite content (first maximum) [7-8]. In the present work, an increment of martensite at $400^{\circ} \mathrm{C}$ has not been because the effect of this phenomenon is so low to be masked by the martensite reversion.

\section{Conclusions}

For increasing time of annealing at $400{ }^{\circ} \mathrm{C}$ the amount of $\alpha^{\prime}$ phase shows a decreasing trend, due to $\alpha^{\prime} \rightarrow \gamma$ reversion, with two maxima after $\approx 4 \times 10^{3} \mathrm{~s}$ and $3.5 \times 10^{4} \mathrm{~s}$ [7]. The present work was carried out to investigate the second maximum by high-temperature XRD and dynamic modulus measurements. The main results can be summarized as follows:

(i) the $\alpha^{\prime} \rightarrow \gamma$ transformation is the prevailing phenomenon occurring during annealing;

(ii) some martensite forms during cooling;

(iii) the martensitic transformation takes place in the temperature range $240-190^{\circ} \mathrm{C}$.

The formation of martensite by cooling involves the presence of composition inhomogeneities, which locally increase $\mathrm{M}_{\mathrm{S}}$ in the zones impoverished of alloying elements. This work confirms previous results [8-9] and further supports the mechanism proposed by Harries [6].

The first maximum was not observed in the examined samples, likely for their very high initial martensite fraction (94\%), however martensite formation was detected during the interme- 
diate annealing steps at 200 and $300^{\circ} \mathrm{C}$ in the second series of XRD experiments.

\section{References}

[1] P. Marshall, Austenitic Stainless Steels-Microstructure and Mechanical Properties, Elsevier, New York, 1984, 30.

[2] A.N. Chukleb, V.P. Martynov, Phys. Met. Metall. 10 (1960) 80.

[3] K.B. Guy, E.P. Butler, D.R.F. West, Met. Sci. 17 (1983) 167.

[4] H. Smith, D.H.R. West, Met. Tech. 1 (1974) 259.

[5] M.W. Bowkett, Ph.D. Thesis, University College, Cardiff (1980),
[6] D.R. Harries, Proceedings of the International Conference on Mechanical Behaviour and Nuclear Applications of Stainless Steels at Elevated Temperatures, Varese-Italy, May (1981).

[7] R. Montanari, Mater. Lett. 10 (1990) 57.

[8] F. Gauzzi, R. Montanari, G. Principi, A. Perin, M.E. Tata, Mater. Sci. Eng. A273-A275 (1999) 443.

[9] C.K. Mukhopadhyay, K.V. Kasiviswanathan, T. Jayakumar, B. Raj, Scripta Metall. Mater. 30 (1994) 303.

[10] A.S. Nowick, B.S. Berry, Anelastic Relaxation in Crystalline Solids, Academic Press, New York, 1972, p. 629.

[11] P.L. Mangonon Jr., G. Thomas, Metall. Trans. 1 (1970) 1587.

[12] R. Montanari, M.E. Tata, unpublished results. 